\title{
Trends in hospitalization of preterm infants with intraventricular hemorrhage and hydrocephalus in the United States, 2000-2010
}

\author{
Eisha Anne Christian ${ }^{1 *}$, Diana Jin', Frank Attenello ${ }^{1}$, Timothy Wen', Steven Cen ${ }^{1}$, William J Mack ${ }^{1}$, Mark D Krieger ${ }^{1,2}$, \\ J Gordon McComb ${ }^{1,2}$
}

From Hydrocephalus 2015

Banff, Canada. 18-21 September 2015

\section{Objective}

Even with improved prenatal and neonatal care, intraventricular hemorrhage (IVH) occurs in approximately $25-30 \%$ of preterm infants, and a subset of these patients develop hydrocephalus. We aim to describe current trends in hospitalization of preterm infants with IVH and post-hemorrhagic hydrocephalus ( $\mathrm{PHH}$ ) using the Nationwide Inpatient Sample (NIS) and Kids Inpatient Database (KID).

\section{Methods}

The KID and NIS databases were combined to generate data for the years $2000-2010$. All neonatal discharges with ICD9-CM codes for preterm birth with IVH alone or with IVH and hydrocephalus were included.

\section{Results}

There were 147,823 preterm neonates with IVH, and 9\% of this group developed hydrocephalus during the same admission. Twenty-five percent and $28 \%$ of patients with Grades 3 and 4 IVH respectively developed hydrocephalus in comparison to $1 \%$ and $4 \%$ of patients with Grades 1 and $2 \mathrm{IVH}$. Thirty-eight percent of patients with $\mathrm{PHH}$ had permanent ventricular shunts inserted. Mortality rates were $4 \%, 10 \%, 18 \%$, and $40 \%$ respectively for Grades 1-4 during initial hospitalization. Length of stay has been trending upward for both groups of IVH (49d in 2000, 56d in 2010) and PHH (59d in 2000, 70d in 2010). Average hospital cost per patient (inflation-adjusted) has also increased from $\$ 201,578$ to $\$ 353,554$ (IVH) and $\$ 260,077$ to $\$ 495,697$ (PHH) over 11 years.

\footnotetext{
* Correspondence: echristi@usc.edu

1 University of Southern California, Los Angeles, CA, USA

Full list of author information is available at the end of the article
}

\section{Conclusion}

The number of admissions of neonates with IVH has increased despite a decrease in the number of preterm births. Rates of hydrocephalus and mortality correlated closely with IVH grade. Incidence of hydrocephalus in preterm infants with IVH remained stable between $8-10 \%$. Over an 11-year period, there was a progressive increase in hospital cost and length of stay for preterm neonates with IVH and PHH with a concurrent increase in the proportion of patients with congenital cardiac anomalies.

\section{Authors' details}

'University of Southern California, Los Angeles, CA, USA. ${ }^{2}$ Children's Hospital Los Angeles, CA, USA.

Published: 18 September 2015

\section{References}

1. Olaya JE, Christian E, Ferman D, Luc Q, Sanger T, Krieger M, Liker M: Deep Brain Stimulation in Children and Young Adults with Secondary Dystonia: The Children's Hospital Los Angeles Experience. Neurosurgical Focus 2013, 35(5):E7.

2. Karas PJ, Mikell CB, Christian E, Liker M, Sheth S: Deep Brain Stimulation: a mechanistic and clinical update. Neurosurgical Focus 2013, 35(5):E1.

3. Christian E, Yu C, Apuzzo ML: Focused Ultrasound: Relevant History and Prospects for the Addition of Mechanical Energy to the Neurosurgical Armamentarium. World Neurosurgery 2014, 82(3-4):354.

4. Christian E, Harris B, Wrobel B, Zada G: Endoscopic endonasal transsphenoidal surgery: implementation of an operative and perioperative checklist. Neurosurgical Focus 2014, 37(4):E1.

5. Christian E, Huang C, Yen C, Acosta FA, Chen TC, Liu JC, Spoonamore M, Wang JC, Hsieh PC: A modified Gaines approach for lumbosacral traumatic spondyloptosis: A historical review and case illustration. J Spine 2014, 3(4).

6. Christian E, Imahiyerobo T, Nallapa S, Urata M, McComb JG, Krieger M: Intracranial hypertension after surgical correction for craniosynostosis: a systematic review. Neurosurgical Focus May 2015.

\section{doi:10.1186/2045-8118-12-S1-01}

Cite this article as: Christian et al:: Trends in hospitalization of preterm infants with intraventricular hemorrhage and hydrocephalus in the United States, 2000-2010. Fluids and Barriers of the CNS 2015 12(Suppl 1):01. 